\title{
Murcha-de-curtobacterium do feijoeiro no Estado de Santa Catarina e reação de genótipos a Curtobacterium flaccumfaciens pv. flaccumfaciens*
}

\author{
Gustavo de Faria Theodoro ${ }^{1}$, Antonio Carlos Maringoni ${ }^{2,3}$
}

\begin{abstract}
${ }^{1}$ Epagri/Centro de Pesquisa para Agricultura Familiar, CP 791, 89801-970, Chapecó, SC; ${ }^{2}$ Faculdade de Ciências Agronômicas, UNESP, Departamento de Produção Vegetal, Setor de Defesa Fitossanitária, CP 237, 18603-970, Botucatu, SP; ${ }^{3}$ Bolsista CNPq. "Parte da Tese de Doutorado do primeiro autor, apresentada à Faculdade de Ciências Agronômicas/UNESP, Botucatu, SP (2004). Autor para correspondência: Gustavo de Faria Theodoro. <theodoro@epagri.rct-sc.br> Data de chegada: 27/09/04. Aceito para publicação em: 15/04/05.
\end{abstract}

\begin{abstract}
Theodoro, G.F.; Maringoni, A.C. Bacterial wilt of common bean in Santa Catarina State, Brazil, and behavior of genotypes to Curtobacterium flaccumfaciens pv. flaccumfaciens. Summa Phytopathologica, v. 32, n. 1, p. 34-41, 2006.

It was evaluated the occurrence of bacterial wilt in localities of Santa Catarina State, during the harvest of 2002/03 and 2003/04, and the behavior of the genotypes BRS Valente, Carioca, CHC 97-29, CHP 97-26, CNPF 8104, Diamante Negro, Empasc 201 - Chapecó, IAPAR 44, IPR Graúna, IPR Juriti, IPR Uirapuru, LP 9728, Pérola, SCS 202 Guará, Sel. CP 9310635, TPS Bionobre, TPS Bonito, TPS Magnífico, TPS Nobre, TPS Soberano and Xamego to Curtobacterium flaccumfaciens pv. flaccumfaciens (Cff), under greenhouse conditions.

Pyatã were used as patterns of resistance to Cff. The evaluations of the symptoms were performed at $5,10,15,20$, and 25 days after inoculation (DAI) and, subsequently, the area under the bacterial wilt progress curve (AUBWPC) was estimated in each genotype. The disease was detected in Campos Novos, Faxinal dos Guedes, Guatambu, Ipuaçu, Ponte Serrada and Tigrinhos. The cultivars SCS 202 - Guará and IPR Juriti showed low wilt severity at 10 DAI. However, at 25 DAI, only the pattern cultivars were resistant and exhibited low AUBWPC.
\end{abstract} The cultivars IAC Carioca Akytã, IAC Carioca Aruã, and IAC Carioca

Additional keywords: Phaseolus vulgaris, bacteria, genetic resistance.

\section{RESUMO}

Theodoro, G.F.; Maringoni, A.C. Murcha-de-curtobacterium do feijoeiro no Estado de Santa Catarina e reação de genótipos a Curtobacterium flaccumfaciens pv. flaccumfaciens. Summa Phytopathologica, v. 32, p. 34-41, 2006.

Avaliou-se a ocorrência da murcha-de-curtobacterium em lavouras de feijoeiro comum em algumas localidades do Estado de Santa Catarina, nas safras 2002/03 e 2003/04, e o comportamento dos genótipos BRS Valente, Carioca, CHC 97-29, CHP 97-26, CNPF 8104, Diamante Negro, Empasc 201 - Chapecó, IAPAR 44, IPR Graúna, IPR Juriti, IPR Uirapuru, LP 9728, Pérola, SCS 202-Guará, Sel. CP 9310635, TPS Bionobre, TPS Bonito, TPS Magnífico, TPS Nobre, TPS Soberano e Xamego perante Curtobacterium flaccumfaciens pv. flaccumfaciens (Cff), em condições de casa-de-vegetação. As cultivares IAC Carioca Akytã, IAC Carioca Aruã e IAC Carioca Pyatã foram empregadas como padrões de resistência a Cff. As avaliações dos sintomas ocorreram aos 5, 10, 15, 20 e 25 dias após a inoculação (DAI) e, posteriormente, foi estimada a área abaixo da curva de progresso da murcha-decurtobacterium (AACPMC), em cada genótipo. Adoença esteve presente nos municípios de Campos Novos, Faxinal dos Guedes, Guatambu, Ipuaçu, Ponte Serrada e Tigrinhos e que, aos 10 DAI, as cultivares SCS 202 - Guará e IPR Juriti mostraram baixa severidade. Porém, aos 25 DAI, somente as cultivares padrões foram resistentes e apresentaram menor AACPMC.

Palavras-chave adicionais: Phaseolus vulgaris, bactéria, resistência genética.

Na safra 2002/03, o Estado de Santa Catarina ocupou o séti- mo lugar entre os estados brasileiros produtores de feijão ( $P h a$ - 
seolus vulgaris L.) e contribuiu com 5,7\% do total de grãos produzidos, com uma produção de 186 mil toneladas de grãos, 144 mil hectares cultivados e produtividade de $1.291,7 \mathrm{~kg} / \mathrm{ha}$ (11). Nesse Estado, o cultivo do feijoeiro é feito principalmente em pequenos estabelecimentos rurais, que empregam mão-deobra de origem familiar. Entre os fatores que têm contribuído para a redução da área cultivada com feijoeiro em Santa Catarina, as doenças de etiologia variada têm se destacado pela ocorrência de condições climáticas favoráveis.

A murcha-de-curtobacterium, causada por Curtobacterium flaccumfaciens pv. flaccumfaciens (Hedges) Collins \& Jones, foi recentemente relatada no Brasil e no Estado de Santa Catarina $(13,19)$ e seu controle está baseado somente no uso de sementes sadias, rotação de culturas e cultivares com algum nível de resistência genética (7). Até poucos anos atrás, não era possível indicar genótipos resistentes à murcha-de-curtobacterium para cultivo no Brasil. Atualmente, tem-se procurado identificar linhagens e cultivares de feijoeiro com resistência à essa bacteriose $(12,16,21)$.

O objetivo deste trabalho foi verificar a ocorrência da murcha-de-curtobacterium em alguns municípios catarinenses e avaliar a reação de linhagens e cultivares de feijoeiro, utilizadas em Santa Catarina, perante C. flaccumfaciens pv. flaccumfaciens.

\section{MATERIALEMÉTODOS}

\section{Murcha-de-curtobacterium do feijoeiro no Estado de Santa Catarina}

Plantas de feijoeiro com sintoma típico de murcha foram obtidas em visitas a lavouras comerciais e experimentais e pelo atendimento de agricultores e técnicos ligados à agropecuária, por ocasião do encaminhamento de amostras para fins de diagnose de doenças, no Laboratório de Fitossanidade da Epagri/ Cepaf. A metodologia de coleta de plantas a campo foi semelhante àquelas descritas por Maringoni \& Komori (17), que procuraram verificar a distribuição de Xanthomonas axonopodis pv. phaseoli e Pseudomonas syringae pv. tabaci em lavouras de feijoeiro no Estado do Paraná. Caminhou-se em zigue-zague por toda a lavoura, indicadas por técnicos de cooperativas e pesquisadores e extensionistas rurais da Epagri. Desta forma, não foi estabelecido um número exato de lavouras de feijoeiro por município e o critério de escolha foi buscar aquelas que pudessem representar os demais feijoais da região.

Após o acondicionamento de plantas inteiras com sintomas de murcha em sacos de papel e o envio ao laboratório, realizaram-se os procedimentos necessários para o isolamento de bactérias da região do colo e/ou da base de pecíolos das plantas doentes, conforme a metodologia descrita por Davis \& Vidaver (5). Após o desenvolvimento de colônias bacterianas em meio de cultura nutriente-sacarose-ágar ou N.S.A (peptona - 5,0 g, extrato de carne - 3,0 g, sacarose- 5,0 g, ágar - $15 \mathrm{~g}$ e água destilada - $1000 \mathrm{~mL}$ ), foi realizada a purificação de $C$. f. pv. flaccumfaciens, permanecendo incubadas a $28^{\circ} \mathrm{C} / 48 \mathrm{~h}$. Realizou-se a coloração diferencial de Gram após o cultivo dos isolados purificados, a fim de verificar se estavam em concordância com a descrição de $C$. $f$. pv. flaccumfaciens (5). Procedeu-se, ainda, o teste de solubilidade em hidróxido de potássio, de forma a complementar e confirmar os resultados da coloração diferencial de
Gram.

Os isolados foram inoculados em plantas de feijoeiro cv. Pérola para avaliar a patogenicidade. Três plantas de feijoeiro foram cultivadas em sacos plásticos para propagação de mudas de frutíferas, preenchidos com $2 \mathrm{~L}$ de solo de mata corrigido e adubado e, aos dez dias após a emergência, os isolados foram inoculados por picadas no epicótilo das plantas com uma alça reta previamente umedecida em colônias bacterianas, cultivadas por $96 \mathrm{~h}$ a $28^{\circ} \mathrm{C}$ em placa de Petri contendo meio de cultura N.S.A., de acordo com a metodologia empregada por Maringoni (16). Foram empregadas plantas de feijoeiro mantidas em três sacos plásticos por isolado e o tratamento testemunha foi representado pela picada com água destilada esterilizada. As plantas foram mantidas em casa-de-vegetação e foi realizado o re-isolamento, em meio de cultura N.S.A., da bactéria presente em plantas sintomáticas, entre 15-30 dias após a inoculação. Os isolados patogênicos foram cultivados em meio de cultura nutriente líquido (peptona - 5,0 g, extrato de carne - 3,0 g e água destilada - $1000 \mathrm{~mL}$ ) com $7 \%$ de $\mathrm{NaCl}$, com o objetivo de verificar a tolerância de $C . f$. pv. flaccumfaciens a essa concentração salina (19). Posteriormente, estes isolados foram cultivados por duas vezes consecutivas em meio de cultura universal de crescimento da Biolog® (BUG), durante $24 \mathrm{~h}$, a $30^{\circ} \mathrm{C}$. Colônias bacterianas desenvolvidas na superfície do meio BUG foram transferidas e homogeneizada em fluído inoculante e a suspensão resultante padronizada por colorimetria, a 20\% de transmitância, no comprimento de onda de $600 \mathrm{~nm}$. Cento e cinqüenta microlitros da suspensão bacteriana foram depositados em cada um dos poços da microplaca (GP2 MicroPlate ${ }^{\mathrm{TM}}$ ), que continha 95 diferentes fontes de carbono. As microplacas foram incubadas em câmara úmida, a $30^{\circ} \mathrm{C}$, durante $24 \mathrm{~h}$. Seguido o período de incubação, foi realizada a leitura de cada um dos poços contendo as diferentes fontes de carbono atribuindo-se os sinais + (reação positiva), - (reação negativa) e \pm (reação variável). As reações obtidas da utilização das diferentes fontes de carbono foram plotadas e analisadas no programa MicroLog2 $2^{\mathrm{TM}}$ System, para identificação de bactérias. Os resultados obtidos foram expressos em índice de similaridade do isolado que estava sendo analisado com um espécime bacteriano identificado existente no banco de dados do programa.

Os locais amostrados, nos quais a bactéria estava presente, foram anotados em um mapa do Estado de Santa Catarina.

Reação de genótipos de feijoeiro a $\boldsymbol{C}$. $\boldsymbol{f}$. pv. flaccumfaciens

Avaliou-se o comportamento dos seguintes genótipos de feijão, do grupo carioca, perante o isolado $\mathrm{FJ} 36$, de $C$. $f$. pv. flaccumfaciens: Carioca, CHC 97-29, TPS Bonito, TPS Magnífico, IPR Juriti, LP 9728, Pérola, SCS 202 - Guará, IAC Carioca Akytã, IAC Carioca Aruã e IAC Carioca Pyatã. Do grupo preto, foram avaliados os genótipos BRS Valente, CHP 97-26, CNPF 8104, Diamante Negro, Empasc 201 - Chapecó, TPS Bionobre, TPS Nobre, TPS Soberano, IAPAR 44, IPR Graúna, IPR 88 - Uirapuru, Sel. CP 9310635 e Xamego.

As sementes foram imersas em solução contendo benomyl a 0,25 g. $\mathrm{L}^{-1}$, durante 5 minutos e colocadas para pré-germinar em papel toalha umedecido a $25^{\circ} \mathrm{C}$, até a emissão da radícula. Cinco sementes pré-germinadas foram transplantadas para sacos plásticos, com 2 L de solo de mata, corrigido e adubado. Realizou-se o desbaste, uma semana após o plantio, mantendo-se três plantas por saco plástico, que permaneceram em casa-de-vegetação. 
Procedeu-se à inoculação das plantas, conforme descrito anteriormente, com o isolado FJ 36, obtido de feijoeiro da cultivar local "Preto Brilhoso Arredondado", em Campos Novos, na safra 2002/ 03. O tratamento testemunha foi representado pelo uso de água destilada, ao invés de inóculo, nas picadas em plantas da cultivar Pérola.

Empregou-se o delineamento experimental de blocos ao acaso com cinco repetições, onde cada parcela experimental foi representada por um saco plástico contendo três plantas. A avaliação dos sintomas ocorreu aos 5, 10, 15, 20 e 25 dias após a inoculação (DAI), empregando-se a escala descritiva adaptada por Maringoni (16). As reações de resistência e de suscetibilidade foram consideradas para notas médias de severidade até 2 e superiores a 2,1, respectivamente. A partir dos valores de severidade obtidos, foi estimada a área abaixo da curva de progresso da murcha-de-curtobacterium em cada genótipo, de acordo com a fórmula: AACPMC $=\Sigma\left\{\left[\left(\mathrm{Y}_{1}+\mathrm{Y}_{2}\right) / 2\right]^{*} \Delta \mathrm{t}\right\}$, onde $\mathrm{Y}_{1}$ e $\mathrm{Y}_{2}$ corresponderam aos valores de severidade para duas avaliações sucessivas dentro do mesmo bloco e $\Delta \mathrm{t}$, o intervalo de tempo entre elas. Os valores de AACPMC foram submetidos à análise de comparação entre médias pelo teste de Tukey, a 5\% de probabilidade. $\mathrm{O}$ controle das pragas que ocorreram durante o ensaio foi feito através de pulverizações com produtos registrados para a cultura.

\section{RESULTADOSE DISCUSSÃO}

\section{Murcha-de-curtobacterium do feijoeiro no Estado de Santa Catarina}

Foram obtidas 46 amostras, representadas por plantas de feijão com sintoma de murcha, oriundas dos municípios de Águas de Chapecó, Caibi, Campos Novos, Chapecó, Palmitos, Ponte Serrada e São Carlos, durante a safra das águas ("safra") de 2002/2003, e dos municípios de Águas de Chapecó, Chapecó, Campos Novos, Faxinal dos Guedes, Guatambu, Ipuaçu, Tigrinhos, Ouro Verde e Ponte Serrada, na safra das águas e da seca (“safrinha") de 2003/04. Porém, no segundo período, houve a prevalência de coletas durante a safra das águas por representar a maior parte da área cultivada com feijoeiro no Estado de Santa Catarina. De acordo com dados do Instituto Cepa (11), a área cultivada com feijão na safra da seca representou $26,4 \%$ e $27,8 \%$ em 2002 e 2003, respectivamente.

Do total das amostras avaliadas, cinco não foram obtidas por meio de coleta a campo, mas encaminhadas por técnicos e produtores rurais ao Laboratório de Fitossanidade da Epagri/ Cepaf para fins de diagnose. As cultivares encontradas nas lavouras foram predominantemente locais $(55,17 \%)$, que se caracterizam por serem adaptadas regionalmente, estarem presentes na maioria dos pequenos estabelecimentos rurais que empregam mão-de-obra de origem familiar, apresentarem grande variabilidade genética e até mesmo genes de resistência a doenças $(24,29)$.

Procurou-se visitar lavouras com feijoeiros em diversas etapas de desenvolvimento e foram coletadas plantas com a primeira e a terceira folha trifoliadas, com botões florais e no início de formação e enchimento das vagens. As plantas doentes geralmente se apresentaram isoladas e somente em uma lavoura de feijão cv. Pérola, localizada no município de Faxinal dos Guedes, foi verificada a ocorrência de um grande número de agregação de plantas com folhas murchas.
Os resultados mostraram que a murcha-de-curtobacterium esteve presente nos municípios de Campos Novos, Faxinal dos Guedes, Guatambu, Ipuaçu, Ponte Serrada e Tigrinhos e se mostrou presente na região centro-oeste e oeste do Estado de Santa Catarina (Figura 1). Apesar de ter ocorrido em municípios com os dois sub-tipos climáticos de Köppen existentes no Estado (Cfa: temperatura média do mês mais quente acima de $22^{\circ} \mathrm{Ce}$, do mais frio, entre $10 \mathrm{e} 15^{\circ} \mathrm{C} ; \mathrm{e} \mathrm{Cfb}$ : temperatura média do mês mais quente abaixo de $22^{\circ} \mathrm{C}$ e, do mais frio, entre -3 e $18^{\circ} \mathrm{C}$ ), os resultados mostraram que a doença ocorreu predominantemente nos municípios caracterizados com o clima sub-tipo Cfb e confirmaram o relato de Leite Jr. et al. (13), que fizeram a primeira constatação da doença em Campos Novos. Conforme Saettler (25), a murcha-de-curtobacterium é favorecida por temperaturas acima de $32^{\circ} \mathrm{C}$ e o maior desenvolvimento da doença é a $37^{\circ} \mathrm{C}$. Com isso, aventa-se a hipótese que a maior freqüência de $C$. $f$. pv. flaccumfaciens em municípios encontrados nas condições de clima $\mathrm{Cfb}$ seja causada por outros fatores que podem ter contribuído na incidência da murcha-de-curtobacterium, como altas pluviosidades, populações de nematóides e/ou outra praga que tenha causado ferimentos nas raízes das plantas, plantas daninhas hospedeiras, dentre outros. Além disso, deve-se relatar que o sistema de cultivo da maioria das lavouras comerciais visitadas nos municípios de clima $\mathrm{Cfb}$ foi o extensivo, em grandes áreas, com o uso de tecnologias e/ou o emprego de sementes oriundas do sistema cooperativo, aparentemente de boa procedência. Já nos municípios sob o clima Cfa, a maioria dos estabelecimentos se caracterizou pela presença da agricultura de subsistência, em pequenas áreas e com o emprego de mão de obra familiar. Em um diagnóstico da produção de sementes de feijão em Santa Catarina, Balardin et al. (1) constataram que a origem da produção apresentou reflexos diretos na qualidade sanitária de sementes de feijão, pois logo após as sementes básicas, as sementes originadas nos estabelecimentos rurais foram as que apresentaram as menores percentagens de ocorrência de patógenos de campo. Possivelmente, por haver a seleção e o uso das sementes produzidas no próprio estabelecimento por um longo período, sementes infectadas por $C$. $f$. pv. flaccumfaciens ainda não foram introduzidas e utilizadas nas lavouras amostradas e localizadas nos municípios de clima Cfa.

Por meio dos testes adotados neste ensaio, foram obtidos oito isolados de C.f. pv. flaccumfaciens (Tabela 1) e todos estes foram patogênicos às plantas de feijão. As que foram feridas mediante picadas somente com água destilada esterilizada não manifestaram sintomas de murcha. Mesmo havendo a prevalência de isolados de C.f. pv. flaccumfaciens de coloração creme, $25,0 \%$ se mostraram com coloração salmão e $12,5 \%$ alaranjada. Variabilidade na coloração de colônias em isolados de $C$. $f$. pv. flaccumfaciens oriundos de lavouras de feijão do Estado de São Paulo também foi verificada por Maringoni (15) e colônias de coloração alaranjada foram obtidas por Schuster \& Christiansen (27), por meio da análise de lotes de sementes de feijão.

Foi possível coletar apenas uma planta, no estádio vegetativo, com C.f. pv. flaccumfaciens, provavelmente pela menor manifestação dos sintomas da doença e pela maior incidência de outros patógenos que incitam murcha. Em lavoura da cv. Ligeirinha em pleno florescimento, localizada no município de Chapecó, foram obtidos quatro isolados com características culturais semelhantes à $C$. $f$. pv. flaccumfaciens de plantas que haviam estado com folhas murchas até o estádio $\mathrm{V}_{4}$. Contudo, não fo- 


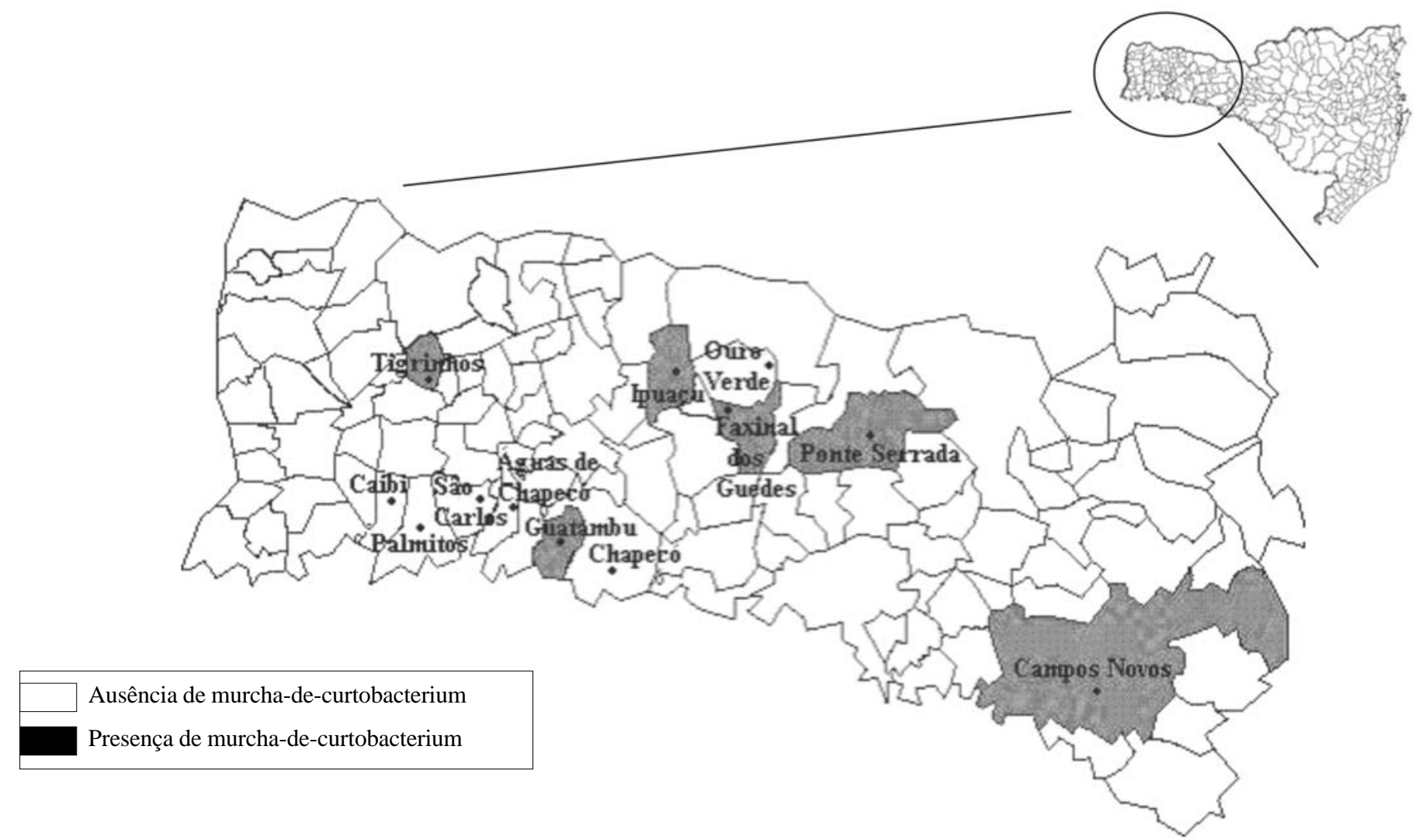

Figura 1 - Ocorrência da murcha-de-curtobacterium em algumas localidades do Estado de Santa Catarina.

Tabela 1 - Características dos isolados de C.f. pv. flaccumfaciens obtidos em lavouras de feijão do Estado de Santa Catarina.

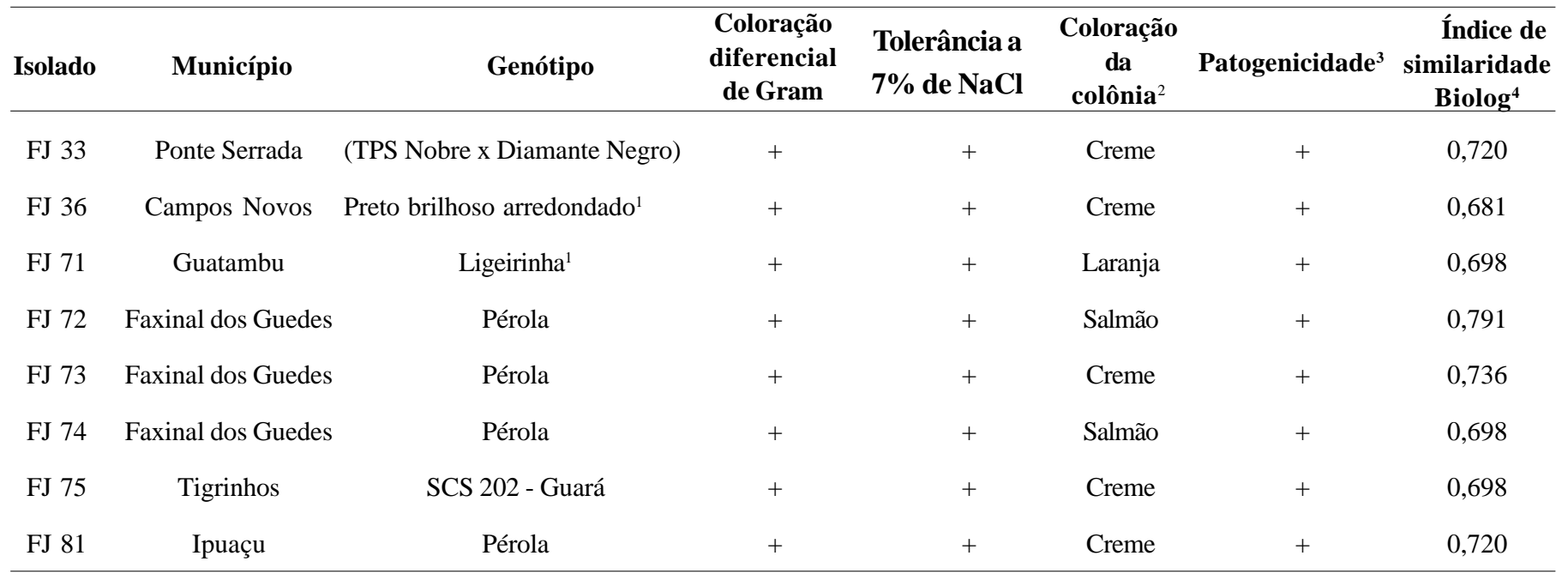

${ }^{1}$ Cultivar local

${ }^{2}$ Meio de cultura nutriente-sacarose-ágar.

${ }^{3}$ Inoculação em plantas de feijoeiro cv. Pérola.

4 Curtobacterium flaccumfaciens (Sistema MicroLog2 $2^{\mathrm{TM}}$ System)

ram considerados pertencentes à espécie em questão porque não foram patogênicos a plantas da cv. Pérola, até os 30 dias após a inoculação. Assume-se que estes isolados poderiam pertencer ao grupo de espécies bacterianas endofíticas, uma vez que existe o relato da presença destes microrganismos em plantas e sementes de feijão (14). Outra possibilidade é o fato de ter havido a prevalência de isolados de $C$.f. pv. flaccumfaciens não patogênicos nos vasos do xilema dessas plantas, possivelmen- 
te com ação bacteriocinogênica. A produção de bacteriocinas foi confirmada para esta espécie por Maringoni \& Kurozawa (18), mediante o emprego de isolados brasileiros e outros provenientes de coleções internacionais.

Apesar dos resultados aqui terem sido baseados em poucos testes laboratoriais, sabe-se da necessidade da adoção de técnicas não empregadas neste trabalho para a identificação de espécies bacterianas com maior precisão. Porém, existe apenas uma espécie bacteriana Gram positiva que causa murcha na cultura do feijoeiro (7), o que sugere que os procedimentos empregados neste ensaio tenham sido relativamente seguros. Além disso, o índice de similaridade entre os isolados obtidos em lavouras de feijoeiro do Estado de Santa Catarina e o espécime bacteriano identificado como Curtobacterium flaccumfaciens, existente no banco de dados do programa Biolog (Sistema Microlog2 ${ }^{\mathrm{TM}}$ System), foram relativamente altos e variaram de 0,681 a 0,720 (Tabela 1).

No momento da coleta, foi observada a região interna do colo da maioria das plantas, mediante corte longitudinal. Foi verificado que nem sempre o sistema vascular das plantas com murcha-de-curtobacterium era semelhante ao das plantas sadias. O escurecimento existente foi mais freqüente em plantas adultas e infectadas por Fusarium spp., identificado por meio da coloração do crescimento micelial e da morfologia dos conídios, em microscópio ótico. Nos casos de infecção mista, como aquela observada na cv. Ligeirinha coletada em Guatambu, o sistema vascular também estava escurecido. Essa informação corroborou com a descrição dos sintomas da murcha-de-fusárium (30) e com a hipótese enunciada por Maringoni \& Rosa (19), sobre a possibilidade de ter havido confusão entre os sintomas causados por C. $f$. pv. flaccumfaciens e Fusarium oxysporum f.sp. phaseoli no Brasil.

Foi verificada predominância de feijoeiros com sintoma de murcha que, provavelmente, estavam infectados por $X$. axonopodis pv. phaseoli, pois a grande parte dos isolamentos realizados por meio da trituração de fragmentos da região do colo resultou no desenvolvimento de colônias bacterianas convexas, mucóides, Gram negativas, de coloração amarelada e algumas produziram um pigmento escuro em meio de cultura (26). Conforme Rava \& Sartorato (22), pode haver murcha em plantas de feijoeiro quando $X$. axonopodis pv. phaseoli passa a colonizar o seu sistema vascular.

Leite Jr \& Behlau (12) constataram a murcha-de-curtobacterium em lavouras de Castro, Wenceslau Braz e Pato Branco e sugeriram a presença de $C$. $f$. pv. flaccumfaciens em outros municípios paranaenses produtores de feijão. Aventa-se esta mesma hipótese para os feijoais catarinenses, uma vez que esta doença esteve presente em 50\% dos municípios amostrados, indicando a adaptabilidade do patógeno ao hospedeiro e aos dois sub-tipos climáticos presentes no Estado de Santa Catarina.

Estes resultados mostraram a elevada importância da murcha-de-curtobacterium para o Estado de Santa Catarina e a necessidade da adoção de medidas para o seu controle.

\section{Reação de genótipos de feijoeiro a $\boldsymbol{C} . \boldsymbol{f}$. pv.flaccumfaciens}

$\mathrm{O}$ resultado referente à reação dos genótipos de feijoeiro ao isolado FJ 36, de C. f. pv. flaccumfaciens, se encontra na Tabela 2. Durante o período de condução deste ensaio, a temperatura esteve elevada dentro da casa-de-vegetação, havendo a necessidade de irrigações periódicas para que não houvesse estresse hídrico nas plantas. Foi verificada a expressão de sintomas em todos os genótipos avaliados e reação de suscetibilidade nas cultivares TPS Nobre, Empasc 201-Chapecó, IPR 88 - Uirapuru, TPS Soberano e Xamego, na primeira avaliação dos sintomas, aos cinco dias após a inoculação. Outros trabalhos também constataram reação de suscetibilidade nas cultivares TPS Nobre (12, 16) e Xamego (16), mas nenhum procurou avaliar os sintomas da murcha-de-curtobacterium precocemente. A cultivar Empasc 201Chapecó foi originada no Instituto Colombiano Agropecuário (ICA), proveniente do cruzamento entre ICA Tuí x S219 N-1 e foi recomendada para Santa Catarina, em 1983. Porém, devido à sua alta suscetibilidade a Fusarium oxysporum f.sp. phaseoli, foi retirada da lista de recomendação de cultivares de feijão, na safra de 2002/03. A cultivar IPR 88 - Uirapuru foi originada do cruzamento entre (IAPAR BAC 29 x PR 1711) x [NEP 2 x (Puebla $173 \times$ Icapijao)] e apresenta resistência ao vírus do mosaico comum, à ferrugem e ao oídio (20). Foi lançada e recomendada recentemente para o Estado do Paraná e tem se destacada, juntamente com a 'IPR Graúna' e 'CNPF 8104', entre os genótipos de feijão do grupo preto mais produtivos em diversos ambientes de Santa Catarina, tanto na primeira quanto na segunda época de cultivo (9). O mesmo comportamento foi atribuído aos materiais LP 9728, IPR Juriti, CHC 97-29 e SCS 202 - Guará (10), do grupo carioca, que também se mostraram suscetíveis à murchade-curtobacterium.

Aos 10 DAI, foi observado que as cultivares IPR Juriti, SCS 202-Guará, IAC Aruã, IAC Akytã e IAC Carioca Pyatã apresentaram notas médias de severidade iguais ou menores que dois. As cultivares lançadas pelo Instituto Agronômico de Campinas permaneceram com baixa nota de severidade até a última avaliação dos sintomas e a maioria das plantas mostrou sintomas de mosaico nas folhas. Schuster et al. (28) verificaram que genótipos tolerantes, como PI 165078 e Terapy Buff (P. acutifolius), mostraram amarelecimento, mas sem a presença de tecidos flácidos. Porém, a partir dos 15 DAI, todas as cultivares, com exceção das lançadas pelo IAC, mostraram suscetibilidade à murcha-de-curtobacterium. Esse comportamento indicou que a presença de algum nível de resistência nas cultivares IPR Juriti e SCS 202-Guará pode ter aumentado o período de incubação da doença. Conforme Bergamin Filho et al. (2), o período de incubação não deve ser considerado um componente da resistência, por não afetar diretamente a taxa reprodutiva do patógeno. Entretanto, inúmeros autores o têm usado por haver correlação entre ambos. O mecanismo de resistência que causou o atraso e/ ou dificultou a colonização de $C$. $f$. pv.flaccumfaciens, em genótipos de feijão resistentes, foi relacionado por Schuster et al. (28) com uma menor quantidade desta bactéria no xilema das plantas, sendo governado por um ou poucos pares de genes (3, 4). Maringoni (15) concordou com esta observação e supôs que, pelo fato das cultivares IAC Akytã, IAC Aruã e IAC Carioca Pyatã apresentarem baixa severidade à murcha-de-curtobacterium, a natureza da resistência fosse oligogênica, semelhante à descrita para a murcha-de-fusarium.

Esses dados corroboraram com os descritos por Maringoni (16), que sugeriu que as cultivares IAC Aruã, IAC Carioca Pyatã e IAC Akytã têm pelo menos um de seus progenitores com resistência à $C$. $f$. pv. flaccumfaciens. Entretanto, Rava \& Costa (21) agruparam as cultivares IAC Carioca Pyatã, IAC Aruã e IAPAR 31 como medianamente resistentes e atribuíram à maior virulência do isolado utilizado a discordância com os resultados obti- 
Tabela 2 - Reação de genótipos de feijoeiro ao isolado FJ 36, de Curtobacterium flaccumfaciens pv. flaccumfaciens.

\begin{tabular}{|c|c|c|c|c|c|c|c|}
\hline \multirow[b]{2}{*}{ Genótipos } & \multicolumn{5}{|c|}{ Severidade } & \multirow[b]{2}{*}{ Reação $^{3}$} & \multirow[b]{2}{*}{$\mathrm{AACPMC}^{4}$} \\
\hline & $\begin{array}{c}\mathbf{5} \\
\text { DAI }^{1}\end{array}$ & $\begin{array}{c}10 \\
\text { DAI }\end{array}$ & $\begin{array}{c}15 \\
\text { DAI }\end{array}$ & $\begin{array}{c}20 \\
\text { DAI }\end{array}$ & $\begin{array}{c}25 \\
\text { DAI }\end{array}$ & & \\
\hline TPS Nobre & $5,20^{2}$ & 8,20 & 9,00 & 9,00 & 9,00 & $\mathrm{~S}$ & $166,50 \mathrm{a}^{5}$ \\
\hline Empasc 201 - Chapecó & 3,73 & 8,60 & 9,00 & 9,00 & 9,00 & $S$ & $164,84 \mathrm{ab}$ \\
\hline IPR 88 - Uirapuru & 3,80 & 7,13 & 9,00 & 9,00 & 9,00 & $\mathrm{~S}$ & $157,67 \mathrm{abc}$ \\
\hline LP 9728 & 1,40 & 7,93 & 8,86 & 9,00 & 9,00 & $\mathrm{~S}$ & $154,97 \mathrm{abcd}$ \\
\hline Diamante Negro & 1,73 & 7,33 & 8,72 & 8,87 & 9,00 & S & $151,42 \mathrm{abcd}$ \\
\hline TPS Soberano &, 390 & 5,93 & 6,80 & 8,60 & 9,00 & $\mathrm{~S}$ & 138,91 abcde \\
\hline TPS Magnífico & 1,07 & 4,73 & 8,33 & 9,00 & 9,00 & $\mathrm{~S}$ & 135,48 abcde \\
\hline CHC 97-29 & 1,20 & 4,60 & 8,32 & 9,00 & 9,00 & $\mathrm{~S}$ & 135,01 abcde \\
\hline BRS Valente & 1,93 & 5,53 & 7,67 & 8,20 & 8,73 & $S$ & 133,67 abcde \\
\hline Sel. CP 9310635 & 0,80 & 5,80 & 7,67 & 8,33 & 8,73 & $S$ & 132,82 abcdef \\
\hline Carioca & 1,53 & 3,94 & 8,20 & 8,87 & 9,00 & $S$ & 131,33 abcdef \\
\hline TPS Bionobre & 1,13 & 4,07 & 8,20 & 8,87 & 9,00 & $\mathrm{~S}$ & 129,49 bcdef \\
\hline TPS Bonito & 1,87 & 3,53 & 7,73 & 8,73 & 8,87 & S & $126,84 \mathrm{cdef}$ \\
\hline Pérola & 0,80 & 3,93 & 7,80 & 8,73 & 8,87 & S & $126,50 \mathrm{cdef}$ \\
\hline IAPAR 44 & 0,40 & 3,07 & 8,07 & 8,87 & 9,00 & S & 124,49 cdef \\
\hline CHP 97-26 & 0,93 & 3,73 & 7,06 & 8,47 & 9,00 & S & $121,13 \mathrm{def}$ \\
\hline Xamego & 2,13 & 4,00 & 6,47 & 7,13 & 7,67 & S & $112,51 \mathrm{ef}$ \\
\hline IPR Juriti & 0,53 & 2,00 & 7,00 & 8,73 & 8,87 & S & 112,15 ef \\
\hline CNFP 8104 & 0,80 & 3,40 & 6,60 & 7,73 & 8,40 & S & 111,67 ef \\
\hline SCS 202 - Guará & 0,40 & 1,60 & 6,47 & 8,73 & 9,00 & S & 107,49 ef \\
\hline IPR Graúna & 0,53 & 2,40 & 5,87 & 7,13 & 7,53 & S & 96,83 ef \\
\hline IAC Carioca Aruã & 0,73 & 0,87 & 1,00 & 1,00 & 1,33 & $\mathrm{R}$ & $19,50 \mathrm{~g}$ \\
\hline IAC Carioca Akytã & 0,00 & 0,87 & 0,93 & 1,00 & 1,20 & $\mathrm{R}$ & $17,01 \mathrm{~g}$ \\
\hline IAC Carioca Pyatã & 0,13 & 0,53 & 0,93 & 1,00 & 1,20 & $\mathrm{R}$ & $15,68 \mathrm{~g}$ \\
\hline Pérola (Testemunha) & 0,00 & 0,00 & 0,00 & 0,00 & 0,00 & - & $0,00^{6}$ \\
\hline CV (\%) & & & & & & & 12,9 \\
\hline
\end{tabular}

'Dias após a inoculação; ${ }^{2}$ Média de severidade de cinco repetiç̃es; ${ }^{3}$ Aos $25 \mathrm{DAI} ; \mathrm{S}=$ Suscetível, $\mathrm{R}=$ Resistente; ${ }^{4}$ Valor médio da área abaixo da curva de progresso da murcha-de-curtobacterium, média de cinco repetições; ${ }^{5}$ Médias seguidas da mesma letra não diferem estatisticamente entre si, pelo teste de Tukey, a 5\% de probabilidade; ${ }^{\circ}$ Valor não incluído na análise estatística.

dos por Maringoni (16). Todavia, essa observação pode não ser consistente, pois Maringoni (16) também verificou que a cultivar IAPAR 31 foi suscetível a dois isolados de $C$. $f$. pv. flaccumfaciens. Leite Jr. \& Behlau (12) relataram que as cultivares IAPAR 14, IAPAR 16 e IAPAR 31 foram resistentes a um isolado de
C. f. pv. flaccumfaciens obtido em lavouras no Estado do Paraná. Aparentemente, há variabilidade patogênica entre isolados de $C$. $f$. pv. flaccumfaciens, mostrando a necessidade de estudos complementares com a seleção de linhagens e cultivares, empregando isolados obtidos em lavouras de regiões onde es- 
sas cultivares sejam recomendadas para cultivo. Outra explicação pode ser atribuída à diferença metodológica entre os trabalhos, uma vez que as avaliações ocorreram aos 12 DAI (21), 25 DAI (18) e aos 21, 35 e 49 DAI (12). Os resultados aqui observados indicam que avaliações precoces podem mascarar o comportamento de genótipos perante $C$. $f$. pv. flaccumfaciens, havendo a necessidade de observar os sintomas pelo menos até os 20 DAI. Isso está de acordo com Coyne et al. (4), quando observaram que algumas plantas de feijoeiro, classificadas como resistentes à murcha-de-curtobacterium, durante a fase de plântula ou pré-florescimento, se tornaram suscetíveis no florescimento. Além disto, Leite \& Behlau (12) inocularam as plantas somente aos 21 dias após a semeadura e empregaram uma escala para a avaliação dos sintomas com três notas. Sabe-se que existe variação na suscetibilidade à murcha-de-curtobacterium, conforme a idade de plantas de feijoeiro, podendo-se observar maior severidade em plantas jovens (23). As condições ambientais também podem ter influenciado as diferenças observadas nesses trabalhos, pois Coyne et al. (3) verificaram que, em condições de temperatura média ao redor de $21^{\circ} \mathrm{C}$, as linhagens PI 165,078 e PI 136,725 se mostraram resistentes à murcha-de-curtobacterium, enquanto que em condições de campo, com temperaturas ao redor de 33 a $38^{\circ} \mathrm{C}$ na fase de formação de vagens, a linhagem PI 136,725 foi suscetível. Temperaturas elevadas influenciaram a expressão precoce dos sintomas da murcha-de-curtobacterium em linhagens de feijoeiros inoculadas, em Nebraska, U.S.A. (4).

Observando os valores médios da AACPMC, foi verificado que houve diferença significativa entre os genótipos avaliados. Os valores de AACPMC variaram de 15,68 a 166,50 e os genótipos TPS Nobre, Empasc 201 - Chapecó, IPR 88 - Uirapuru, LP 9728, Diamante Negro, TPS Soberano, TPS Magnífico, CHC 9729 e BRS Valente foram as que apresentaram as maiores áreas, indicando maior suscetibilidade à doença. Esses valores de AACPMC foram correspondentes às notas de severidade, pois todas as cultivares, com exceção da 'Diamante Negro', 'TPS Soberano'e 'BRS Valente', apresentaram-se com a nota máxima logo aos 20 DAI.

Pode-se afirmar que os genótipos Sel. CP 9310635, Carioca, TPS Bionobre, TPS Bonito, Pérola, IAPAR 44, CHP97-26, Xamego, IPR Juriti, CNFP 8104, SCS 202 - Guará e IPR Graúna foram aqueles que, apesar de terem sido suscetíveis ao isolado FJ 36, tiveram valores de AACPMC relativamente baixos. A cultivar SCS 202 - Guará se destacou dentre os genótipos que tiveram nota máxima de severidade, ao final das avaliações, por apresentar o menor valor médio da AACPMC, proporcionado pela baixa severidade da doença até os 10 DAI. A cultivar SCS 202-Guará foi originada pela hibridação da cultivar Carioca versus a linhagem TPS 87-77 e obteve recentemente sua recomendação para cultivo em todas as regiões produtoras de feijão em Santa Catarina, principalmente por se mostrar altamente produtiva em relação às demais cultivares do grupo carioca e pela resistência às raças 7, 73, 89 e 95 de Colletotrichum lindemuthianum (6). Acredita-se que a linhagem TPS 87-77 possua algum nível de resistência à murcha-de-curtobacterium, uma vez que a 'Carioca' foi suscetível à doença neste e em outros trabalhos encontrados na literatura $(12,16,21)$. As três cultivares resistentes à murcha-decurtobacterium foram as que se mostraram com as menores AACPMC (Tabela 2).

Assim, houve reação de suscetibilidade em $87,5 \%$ das culti- vares avaliadas e, dentre as suscetíveis, destacaram-se as que provavelmente possuíram um nível de resistência horizontal capaz de atrasar a colonização dos vasos do xilema. Os resultados aqui obtidos indicam que a murcha-de-curtobacterium, sob condições ambientais favoráveis, pode representar uma séria ameaça às lavouras de feijão de Santa Catarina, pois nenhuma das cultivares recomendadas atualmente (8) foi resistente à $C$. $f$. pv. flaccumfaciens.

\section{REFERÊNCIAS BIBLIOGRÁFICAS}

1. Balardin, R.S.; Dal Piva, C.A.; Ogliari, P.J. Diagnóstico da produção de sementes de feijão em Santa Catarina. Florianópolis: Epagri, 1992. 38p. (Boletim técnico, 61)

2. Bergamin Filho, A.; Menten, J.O.M.; Mendes, B.M.J. Avaliação de resistência a fitopatógenos. Summa Phytopathologica, Piracicaba, v.10, p.137-154, 1984.

3. Coyne, D.P.; Schuster, M.L.; Estes, L.W. Effect of maturity and environment on the genetic control of reaction to wilt bacterium in Phaseolus vulgaris L. crosses. Journal of the American Society for Horticultural Science, Alexandria, v.88, p.393-399, 1966.

4. Coyne, D.P.; Schuster, M.L.; Young, J.O. A genetic study of bacterial wilt (Corynebacterium flaccumfaciens var. aurantiacum) tolerance in Phaseolus vulgaris crosses and the development of tolerance to two bacterial diseases in beans. Journal of the American Society for Horticultural Science, Alexandria, v.87, p.279-85, 1965.

5. Davis, M.J.; Vidaver, A.K. Coryneform plant pathogens. In: SCHAAD, N.W., JONES, J.B., CHUN, W. (Ed.) Plant pathogenic bacteria. 3ed, St.Paul: APS Press, 2001. p.218-235.

6. Elias, H.T.; Hemp, S., Flesch, R.D.; Nicknich, W.; Alexandre, A.D. SCS 202 - Guará: nova cultivar de feijoeiro para o Estado de Santa Catarina. In: Reunião Técnica Catarinense de Milho e Feijão, 4. 2003, Lages. Resumos expandidos ... Lages: Universidade para o Desenvolvimento do Estado de Santa Catarina, Centro de Ciências Agroveterinárias, 2003. p.320-322.

7. Hall, R. (Ed.) Compendium of bean diseases. St.Paul: APS Press, 1991. 73p.

8. Hemp, S.; Elias, H.T.; Nicknich, W.; Balbinot Jr., A.A.; Alexandre, A.D.; Rowe, E.; Gallotti, G.J.M.; Crispim, J.E. Feijão. In: EPAGRI. Avaliação de cultivares para o Estado de Santa Catarina 2004/2005. Florianópolis: Epagri, 2004. p.69-77.

9. Hemp, S.; Nicknich, W.; Alexandre, A.D.; Rowe, E.; Balbinot Jr., A.A.; Crispim, J.E.; Nesi, C.N. Ensaio estadual de linhagens e cultivares de feijão preto em Santa Catarina: VCU - 2002/03. In: Reunião Técnica Catarinense de Milho e Feijão, 4. 2003, Lages. Resumos expandidos ... Lages: Universidade para o Desenvolvimento do Estado de Santa Catarina, Centro de Ciências Agroveterinárias, 2003a. p.301-303.

10. Hemp, S.; Nicknich, W.; Alexandre, A.D.; Rowe, E.; Crispim, J.E.; Nesi, C.N. Ensaio estadual de linhagens e cultivares de feijão do grupo carioca em Santa Catarina: VCU - 2002/03. In: Reunião Técnica Catarinense de Milho e Feijão, 4. 2003, Lages. Resumos expandidos ... Lages: Universidade para o Desenvolvimento do Estado de Santa Catarina, Centro de Ciências Agroveterinárias, 2003b. p.306-310.

11. Instituto Cepa. Feijão. In: __ . Síntese anual da agricultura de Santa Catarina - 2002-2003. Florianópolis: Instituto CEPA, 2003. p.49-62.

12. Leite Júnior, R.P.; Behlau, F. Caracterização da murcha-de-curto- 
bacterium do feijoeiro no Paraná. In: Reunião Sulbrasileira de Feijão, 5. 2001, Londrina. Anais ... Londrina: Iapar, 2001. p.50-54.

13. Leite Júnior, R.P.; Meneguim, L.; Behlau, F.; Rodrigues, S.R.; Bianchini, A. Ocorrência de Curtobacterium flaccumfaciens pv. flaccumfaciens em feijoeiro no Paraná e Santa Catarina. Fitopatologia Brasileira, Fortaleza, v.26, supl., p.303, 2001. (Resumo)

14. Mariano, R.L.R.; Assis, S.M.P.; Mello, M.R.F.; Moura, F.F.; Andrade, A.Q.V.; Silva, G. Método de isolamento de bactérias endofíticas. Fitopatologia Brasileira, Fortaleza, v.22, supl., p.235, 1997. (Resumo).

15. Maringoni, A.C. Caracterização de isolados de Curtobacterium flaccumfaciens pv. flaccumfaciens e avaliação da resistência de cultivares de feijoeiro comum à murcha-de-curtobacterium. 2000. 73f. Tese (Livre-Docência). Faculdade de Ciências Agronômicas, Universidade Estadual Paulista, Botucatu.

16. Maringoni, A.C. Comportamento de cultivares de feijoeiro comum à murcha-de-curtobacterium. Fitopatologia Brasileira, Fortaleza, v.27, n.2, p.157-162, 2002.

17. Maringoni, A.C.; Komori, N. Levantamento das bacterioses do feijoeiro no Estado do Paraná. Fitopatologia Brasileira, Brasília, v.14, n.3/4, p.241-244, 1989.

18. Maringoni, A.C.; Kurozawa, C. Tipificação de isolados de Curtobacterium flaccumfaciens pv. flaccumfaciens por bacteriocinas. Pesquisa Agropecuária Brasileira, Brasília, v.37, n.9, p.1339-1345, 2002.

19. Maringoni, A.C.; Rosa, E.F. Ocorrência de Curtobacterium flaccumfaciens pv. flaccumfaciens em feijoeiro no Estado de São Paulo. Summa Phytopathologica, Jaboticabal, v.23, p.160-162, 1997.

20. Moda-Cirino, V.; Oliari, L.; Fonseca Júnior, N. S.; Lollato, M. A. IPR88 Uirapuru common beans. Crop Breeding And Applied Biotechnology, Londrina, v.1, n.2, p.205-206, 2001.

21. Rava, C.A.; Costa, J.G.C. Reação de cultivares à murcha-de-curtobacterium. In: Reunião Técnica Catarinense de Milho e Feijão, 4.
2003, Lages. Resumos expandidos ... Lages: Universidade para o Desenvolvimento do Estado de Santa Catarina, Centro de Ciências Agroveterinárias, 2003. p.246-247.

22. Rava, C.A.; Sartorato, A. Crestamento bacteriano comum. In: Sartorato, A.; Rava, C.A. (Ed.) Principais doenças do feijoeiro comum e seu controle. Brasília: EMBRAPA, 1994. p.217-242.

23. Rickard, S.F.; Walker, J.C. Mode of inoculation and host nutrition in relation to bacterial wilt of bean. Phytopathology, St. Paul, v.55, p.174-178, 1965.

24. Rodrigues, L.S.; Antunes, I.F.; Teixeira, M.G.; Silva, J.B. Divergência genética entre cultivares locais e cultivares melhoradas de feijão. Pesquisa Agropecuária Brasileira, Brasília, v.37, n.9, p.12751284, 2002.

25. Saettler, A.W. Bacterial wilt. In: Hall, R. (Ed.) Compendium of bean diseases. St.Paul: APS Press, 1991. p.31.

26. Schaad, N.W.; Jones, J.B.; Lacy, G.H. Xanthomonas. In: Schaad, N.W.; Jones, J.B.; Chun, W. (Ed.) Plant pathogenic bacteria. 3 ed, St.Paul: APS Press, 2001. p.175-2001.

27. Schuster, M.L.; Christiansen, D.W. An orange colored strain of Corynebacterium flaccumfaciens causing bean wilt. Phytopathology, St. Paul, v.47, p.51-53, 1957.

28. Schuster, M.L.; Coyne, D.P., Singh, K. Population trends and movement of Corynebacterium flaccumfaciens var. aurantiacum in tolerant and susceptible beans. Plant Disease Reporter, v.48, n.10, p.823-827, 1964.

29. Theodoro, G.F. Reação de cultivares locais de feijão a Xanthomonas axonopodis pv. phaseoli, em condições de campo. Revista Brasileira de Agrociência, Pelotas, v.10, n.3, p.373-375, 2004.

30. Zambolim, L.; Costa, H.; Vale, F.X.R. Feijão comum: podridão, tombamento e murcha causados por fungos do solo. In: Vale, F.X.R.; Zambolim, L. (Ed.) Controle de doenças de plantas: grandes culturas. Viçosa: UFV, 1997. v.1, p.375-402. 